\title{
Factor ANd item Response theory analysis of the Protean and Boundaryless Career Attitude Scales
}

\section{Authors:}

Gideon P. de Bruin

Morné Buchner

\section{Affiliations:}

${ }^{1}$ Department of Industrial Psychology and People Management, University of Johannesburg, South Africa

\section{Correspondence to:}

Gideon de Bruin

email:

deondb@uj.ac.za

\section{Postal address:}

Department of Industrial Psychology and People

Management, University of Johannesburg, PO

Box 524, Auckland Park, Johannesburg 2006,

South Africa

\section{Keywords:}

contemporary careers;

Rasch analysis; South

Africa; dimensionality;

latent trait analysis

\section{Dates:}

Received: 08 Nov. 2009

Accepted: 20 Sept. 2010

Published: 03 Dec. 2010

How to cite this article: De Bruin, G.P., \& Buchner, M. (2010). Factor and item response theory analysis of the Protean and Boundaryless Career Attitude Scales. SA Journal of Industrial Psychology/SA Tydskrif vir Bedryfsielkunde, 36(2), Art. \#932, 11 pages. DOI: 10.4102/sajip v36i2.932

This article is available at: http://www.sajip.co.za

(c) 2010. The Authors. Licensee: OpenJournals Publishing. This work is licensed under the Creative Commons Attribution License.

\begin{abstract}
Orientation: The concepts of the Protean Career and the Boundaryless Career show potential as frameworks for research and practice in the contemporary world of work. Briscoe, Hall and DeMuth (2006) developed the Protean and Boundaryless Career Attitude Scales, which consist of the SelfDirected Career Management, Values Driven, Boundaryless Mindset and Mobility Preference subscales. However, the standardisation and replication studies conducted by Briscoe et al., left some questions unanswered in terms of the psychometric properties of the subscales.
\end{abstract}

Research purpose: This study examines the psychometric properties of the Protean and Boundaryless Career Attitude Scales with the aim of clarifying the structure of the scales, examining the quality of the items and evaluating the measurement precision of the scales.

Research design, approach and method: Responses of adults to the items of the Protean and Boundaryless Career Attitude Scales were analysed with factor analytic and Rasch item response model techniques.

Main findings: Factor and Rasch analyses revealed that three of the four postulated dimensions were replicated, but the Values Driven dimension split into two factors. Misfitting items were identified and sources of their misfit were uncovered. The Rasch analysis showed that three of the four subscales provide most of their psychometric information at the lower ends of their respective latent traits (where relatively few persons are located). Hence, the trait estimates of persons with low scores are more precise than those of persons with high scores.

Practical/managerial implications: Overall, the quality of the Protean and Boundaryless Career Attitude Scales is satisfactory, but some aspects that may be improved are identified. Researchers may use at least three of the four subscales with confidence, but more work is possibly needed on the Values Driven subscale.

Contribution/value-add: The study provides researchers with information on the psychometric properties of the Protean and Boundaryless Career Attitude Scales. The study also highlights ways in which the scales may be improved.

\section{INTRODUCTION}

The aim of this study was to examine the internal psychometric properties of the Protean and Boundaryless Career Attitude Scales of Briscoe, Hall and De Muth (2006). The Protean Attitude Scale consists of the Self-Directed Career Management (SDCM) and Values Driven (VD) subscales, whereas the Boundaryless Attitude Scale consists of the Mobility Preference (MP) and Boundaryless Mindset (BM) subscales. Standardisation and replication studies conducted by Briscoe et al. (2006) left unanswered some questions about the dimensionality of the subscales, the quality of the individual items and the measurement precision of the subscales across their respective latent trait continuums. It is hoped that by finding answers to these questions, this study will contribute towards the validation of the Protean and Boundaryless Career Attitude Scales and stimulate further research on the protean and boundaryless career concepts.

\section{Background to the study}

Briscoe, Hall and DeMuth (2006) introduced the Protean and Boundaryless Career Attitude Scales to operationalise the concept of protean (Hall, 1976; 2002) and boundaryless (Arthur, 1994) career. The protean career refers to a career driven and developed by the individual and not by the organisation. On the other hand, the boundaryless career transcends traditional psychological and physical boundaries associated with the career concept (Baruch, 2006).

The protean and boundaryless career concepts are useful for the description and understanding of careers in a working/organisational environment that is becoming increasingly fluid and unpredictable (Baruch, 2006). Until recently, however, there were no scales with which to measure these concepts. Briscoe et al. (2006) expressed the hope that the new scales will serve to stimulate empirical research in this area. Much of the success of such research efforts will rely on the accuracy and precision with which the scales operate. Moreover, the general usefulness of the protean and boundaryless career concepts may be tied to the transportability of the constructs and the corresponding scales beyond the borders of the United States of America.

The remainder of the introduction examines the contemporary world of work and the challenges that it poses to individual career development. Secondly, the meaning of the protean and boundaryless career concepts is explicated. Thirdly, Briscoe et al.'s (2006) description of the development and initial validation of the four new scales are discussed. Finally, the explicit research goals of the study are presented. 


\section{The contemporary world of work}

Traditionally, individual careers in organisations were seen as linear, predictable and secure; an individual entered an organisation and strove to rise through the ranks in an attemp to reach higher positions with clearly defined boundaries. Individuals who performed satisfactorily could be expected to be promoted. An employee's loyalty was rewarded by an organisation in the form of reciprocated loyalty. The implicit psychological contract, which refers to a set of mutual expectations between the individual and the employer (Hall \& Mirvis, 1996), stipulated that as long as employees provided satisfactory work they could rely on long-term employment with the prospect of promotion in the organisation (Baruch, 2006; Hansen, 1997).

In contrast, contemporary careers appear to be more unpredictable, non-linear and vulnerable. Whereas the psychological contract between individual and organisation used to be long-term and relational, it has become short-term and transactional. The new psychological contract requires individuals to engage in continuous learning and to modify their work-related self-perceptions and identities (Baruch \& Hall, 2004; Granrose \& Baccili, 2006). In the contemporary world of work, organisations can expect employees to be loyal only as long as the employee's short-term expectations are met. In turn, individuals can expect organisations to be loyal only as long as their skills and performance fulfil the organisation's current needs (Hall \& Mirvis, 1996).

One consequence of the changed psychological contract is that employees' job insecurity has increased (Baruch, 2006). During the 20th century, employees might have expected the organisation to plan and control their careers, but in an era of increased uncertainty they need to take greater responsibility for their own career development. Hansen (1997) emphasised that because individuals

can no longer rely on their work for security and stability, [they] will become self-directed persons who develop their own careers, gain respect for others and value difference. They will learn to expect change.

(Hansen, 1997, p. 247)

Employees will need to become increasingly adaptable and multiskilled, which implies that continuous professional development and learning how to learn will take on greater importance in individuals' careers. Hall and Mirvis (1996) describe this as a shift from the traditional or organisational career to the protean career.

\section{The protean career attitude}

Hall $(1976 ; 2004)$ defined the protean career as a career where the individual, rather than the organisation, is in charge Protean individuals value individual freedom and growth and define career success in terms of psychological criteria, such as the degree of job satisfaction, self-actualisation, personal accomplishment and a feeling of fulfillment (Hall \& Chandler, 2005; Hall \& Mirvis, 1996). This description contrasts with a more traditional view where career success is defined in terms of external criteria such as promotions, salary and occupational status.

In operationalising the protean career attitude, Briscoe et al. (2006) distinguished two key components, namely, (1) an attitude of self-directedness in terms of managing one's own career and (2) a values driven attitude where the individual's own values, rather than the values of the organisation, drive the career. The first component, namely Self-Directed Career Management is tied to the meta-competency of adaptability and is seen in individuals' ability to adapt to changing conditions and to take responsibility for their own career development. The second component, namely Values Driven, is tied to the metacompetency of self-awareness and is seen when individuals' personal values guide their careers and become the yardstick against which they measure their career success (Hall \& Chandler, 2005).

\section{The boundaryless career attitude}

The boundaryless career refers to the

crossing of objective and subjective dimensions of career at multiple levels of analysis, including organisational position, mobility, flexibility, the work environment and the opportunity structure while at the same time de-emphasising reliance on organisational promotions and career paths.

(Briscoe et al., 2006, p. 2)

Arthur, Khapova and Wilderom (2005) emphasised that the boundaryless career concept refers to mobility across physical and psychological career boundaries. Sullivan and Arthur (2006) describe physical mobility as the actual movement across boundaries between organisations, jobs and departments, whereas psychological mobility refers to the perceived capacity to make such career transitions and changes. Hence, individuals who measure high in boundarylesness may be expected to initiate and pursue work-related relationships across physical organisational boundaries, whereas individuals who measure low in boundarylesness may prefer to pursue their careers within traditional organisational boundaries. However, individuals may harbour a boundaryless mindset without actually leaving their current organisation (Baruch, 2006; Inkson, 2006; Sullivan \& Arthur, 2006). A mindset such as this may be seen in individuals who reject traditional ideas about hierarchically defined career success and advancement within organisations, or in individuals 'like ... academics or carpenters, that draw validation - and marketability - from outside the present employer' (Sullivan \& Arthur, 2006, p. 20)

The development and validation of the self-directed career management, values driven, boundaryless mindset and mobility preference subscales

Briscoe et al. (2006) collected and analysed data in three waves in terms of constructing and validating the SDCM, VD, BM and MP subscales. The data of the first wave, the standardisation study, were used for the construction of the four subscales. The data of the second wave, the replication study, were used to confirm the factor structure of the subscales and to check the reliabilities. The data of the third wave were used to examine the relations of the four subscales with external criteria. In the paragraphs that follow, the results of the standardisation and replication studies are examined more closely.

\section{The standardisation study}

Briscoe et al. (2006) subjected responses to items written to reflect the SDCM and VD concepts to a principal components analysis and items written to reflect the BM and MP concepts to a separate principal components analysis. In the analysis of the SDCM and VD items, two components were retained (on the basis of the eigenvalues-greater-than-one criterion and the screetest) and rotated eight SDCM items and seven VD items. One of the VD items was subsequently dropped. The two components corresponded strongly with the theoretical SDCM and VD subscales, but two items had component loadings $<0.30$ on the VD scale (in the present study these two items are numbered item 9 and item 11, respectively). The reliabilities (Cronbach's coefficient alpha) of the SDCM and VD subscales for the total standardisation sample were 0.81 and 0.69 , respectively. The relatively low reliability of the VD scale suggests that the common factor underlying the items is not very strong.

Briscoe et al. (2006) also retained two components in their analysis of responses to the BM and MP items. They rotated eight BM items and five MP items, which constitute the final BM and MP subscales. The two components corresponded strongly with the corresponding BM and MP subscales. The reliabilities of the BM and MP subscales for the total standardisation sample were 0.89 and 0.76 , respectively. 


\section{The replication study}

The data of the replication sample were subjected to a confirmatory factor analysis (which is based on the common factor model), where four factors corresponding with the SDCM, VD, BM and MP subscales were specified. Each item was specified to load its corresponding factor only. Briscoe et al. (2006) reported that model fitted the data, that all the items had statistically significant factor pattern coefficients and that the correlations between all the factors were statistically significant. The reliabilities of the four subscales in the total replication sample were as follows:

- $\quad$ SDCM, $\alpha=0.75$

- $\mathrm{VD}, \alpha=0.70$

- $\mathrm{BM}, \alpha=0.87$

- $\mathrm{MP}, \alpha=0.74$.

\section{Unanswered questions}

Three aspects of the exploratory and confirmatory factor analyses reported by Briscoe et al. (2006) raise questions about the dimensionality of the SDCM, VD, MP and BM subscales. Firstly, Briscoe et al. chose the principal components model rather than the common factor model for their exploratory analyses. Secondly, the items of the four subscales were not jointly analysed in an exploratory analysis. Thirdly, the fit of the confirmatory factor analysis reported by Briscoe et al. was unsatisfactory.

On a conceptual level principal components analysis is appropriate if the aim is the reduction of a large number of variables into a smaller number of summary variables. Common factor analysis, on the other hand, is appropriate if the aim is the identification of latent traits that account for the covariances of observed variables (Wegener \& Fabrigar, 2000). The principal components model analyses the total variance of a variable and therefore does not distinguish between error variance and common variance. When items are analysed, it may lead to inflated loadings of the items and to a distorted picture of the strength of the relations between items and the components (Gorsuch, 1997). In contrast, the common factor model separates error variance from the common variance and analyses only the common variance of the variables (Cudeck, 2000). Given that responses to individual items are generally unreliable and contain much error variance, the common factor model may give a better representation of the sources of common variance underlying the items of the four subscales (Gorsuch, 1997). Against this background, low component loadings of some items in the Briscoe et al. (2006) standardisation sample are potentially problematic. A common factor analysis might reveal these items to have even weaker loadings.

An added advantage of the common factor model is that it provides statistically based methods for determining the number of factors to retain, such as the likelihood chi-square test, the Root Mean Square Error of Approximation (RMSEA) and the Expected Cross Validation Index (ECVI). These methods, together with a parallel analysis (cf. O'Connor, 2000), possibly constitute more sophisticated methods than the eigenvaluesgreater-than-one criterion and the scree-test and may detect sources of common variance among the items that Briscoe et al. (2006) were unable to detect.

Briscoe et al. (2006) chose to analyse the two protean attitude scales and the two boundaryless attitude subscales in two separate principal components analyses. Overall, the results provided support for the validity of the four subscales. However, a joint analysis of all 27 items might have uncovered additional sources of common variance across the two sets of scales and/ or might have detected items that have loadings on unintended factors. Failure to detect such additional - and often unwanted - sources of common variance and/or problem items, can lead to factors that have different meanings than originally intended and these 'errors' may lead to distorted or unsatisfactory results in subsequent analyses.
Briscoe et al. did subject the responses of a new sample to the items of all four subscales to a confirmatory factor analysis and reported the following fit indices:

- $\quad$ RMSEA $=0.08$

- $\quad$ Comparative Fit Index $(\mathrm{CFI})=0.91$

- $\quad$ Incremental Fit Index (IFI) $=0.91$

- $\quad$ Normed Fit Index $(\mathrm{NFI})=0.88$.

These values fall short of $\mathrm{Hu}$ and Bentler's (1999) recommendations of RMSEA $<0.06$ and a CFI $>0.95$. Against this background Briscoe et al.'s model does not appear to fit the data very well. The results of an unrestricted common factor analysis of all the items together may provide important clues in regard to the sources of the misfit (McDonald, 2005).

A further aspect that remains unanswered is the measurement precision of the four subscales across their respective latent trait continuums. Briscoe et al. (2006) reported classical test theory reliability coefficients for each of the four subscales, but these coefficients give a single estimate of a scale's measurement precision for all persons and therefore assume that each individual's standing on the latent trait is estimated with equal precision. In reality, however, a scale is likely to measure with varying degrees of precision at different points on the underlying latent trait continuum (Embretson \& Reise, 2000).Item response theory acknowledges that a scale does not measure with equal precision across the entire range of the underlying trait. This is made explicit by the test information function curve, which indicates the amount of information that a test or scale provides at different points on the latent trait continuum (Wilson, 2005). Test information curves may provide important clues as to how well the SDCM, VD, MP and BM subscales function and how they may be improved.

\section{Aims of the study}

The present study aims to shed light on, (1) the dimensionality of the items comprising the SDCM, VD, MP and BM subscales, (2) whether each item is a satisfactory indicator of its postulated factor or latent trait and (3) the measurement precision of each subscale across the latent trait continuum. Jointly, these aims are related to the construct validity and measurement precision of the protean and boundaryless career concepts and the scales that operationalise them. A secondary aim of the study is to examine the cross-cultural portability of the protean and boundaryless constructs from the North American context to the South African context.

\section{RESEARCH DESIGN}

\section{Research approach}

This study may be characterised as a psychometric study where the focus falls on the internal psychometric properties of psychological scales.

\section{Research method}

\section{Research participants}

Research participants included 427 adult workers (301 men and 126 women) in a large multi-national petro-chemical organisation. The mean age was 41.29 years $(S D=9.42$ years $)$. The distribution in terms of race was as follows: Black $(n=94)$, White $(n=302)$, Indian $(n=13)$ and Coloured $(n=8)^{1}$. Ten participants did not specify their race. The participants represented a wide variety of job families, with the majority belonging to Engineering $(n=$ $164)$, Financial $(n=93)$ and Technical $(n=65)$. The full spectrum of the managerial hierarchy was covered: non-management $(n=$ $101)$, junior management $(n=158)$, middle management $(n=141)$ and senior management $(n=26)$. One person did not indicate their management level.

Proportionally, female participants and Black participants were overrepresented in the non-management level and 
underrepresented in the middle and senior management levels. The underrepresentation of Black employees in the higher management levels may be seen as a legacy of a previous political and social dispensation, where White South Africans had access to the majority of the educational, economic and material resources of the country.

\section{Measuring instruments}

Protean career attitude: The protean career attitude is operationalised by two subscales: Self-Directed Career Management (SDCM) and Values Driven (VD). The SDCM consists of eight Likert-type items to which participants respond on a five-point scale with ordered categories $(1=$ To little or no extent, 2 = To a limited extent, 3 = To some extent, 4 , To a considerable extent, $5=$ To a great extent). The VD scale consists of six Likert-type items that employs the same fivepoint response scale. For the SDCM, Briscoe et al. (2006) reported reliability coefficients (as estimated by Cronbach's coefficient alpha) for six different samples.

The first three samples constituted the standardisation group, whereas the fourth, fifth and sixth samples constituted a replication group:

- Undergraduate sample $1, \alpha=0.82$

- $\quad$ MBA sample $1, \alpha=0.75$

- Executive sample 1, $\alpha=0.86$

- Undergraduate sample $2, \alpha=0.76$

- $\quad$ MBA sample 2, $\alpha=0.75$

- $\quad$ EMBA sample 2, $\alpha=0.75$.

Overall, these reliabilities appear satisfactory for research purposes. The corresponding reliability coefficients for the VD scale were:

- Undergraduate sample $1, \alpha=0.61$

- $\quad$ MBA sample $1, \alpha=0.76$

- Executive sample 1, $\alpha=0.71$

- Undergraduate sample $2, \alpha=0.68$

- $\quad$ MBA sample $2, \alpha=0.71$

- $\quad$ EMBA sample 2, $\alpha=0.70$.

These reliabilities are lower than those of the SDCM, but may be regarded as marginally adequate for research purposes.

Boundaryless career attitude: The boundaryless career attitude is operationalised by two subscales: Boundaryless Mindset (BM) and Mobility Preference (MP). The BM and MP consist of eight and five Likert-type items, respectively. Participants respond on the same five-point scale with ordered categories that is used for the SDCM and VD subscales, but all the items of the MP scale need to be reverse scored. For the BM, Briscoe et al. (2006) reported the following reliability coefficients (as estimated by Cronbach's coefficient alpha) for six different samples:

- Undergraduate sample $1, \alpha=0.87$

- $\quad$ MBA sample $1, \alpha=0.87$

- Executive sample 1, $\alpha=0.84$

- Undergraduate sample $2, \alpha=0.86$

- $\quad$ MBA sample 2, $\alpha=0.87$

- $\quad$ EMBA sample 2, $\alpha=0.86$.

Overall, these reliabilities appear satisfactory for research purposes. The corresponding reliability coefficients for the MP scale were:

- Undergraduate sample $1, \alpha=0.66$

- $\quad$ MBA sample $1, \alpha=0.78$

- Executive sample 1, $\alpha=0.52$

- Undergraduate sample $2, \alpha=0.70$

- $\quad$ MBA sample $2, \alpha=0.79$

- $\quad$ EMBA sample 2, $\alpha=0.63$.

There appears to be much variability in the reliability coefficients of the MP scale, suggesting that the measurement precision of the scale is sensitive to contextual differences.

\section{Research procedure}

The Protean and Boundaryless Career Attitude Scales formed part of a larger battery of psychometric instruments, which were administered and interpreted as part of a strategic leadership development project in a large multi-national petro-chemical organisation. Data were collected in group sessions under the supervision of professional psychologists. Participants received feedback from professional psychologists and all the data were treated confidentially.

\section{Statistical analysis}

Confirmatory factor analysis: As an initial step, we examined whether each of the four subscales were unidimensional by fitting a single-factor Spearman model to each of the four item sets (cf. Anderson \& Gerbing, 1982; McDonald, 1999). The fit of the Spearman models was judged by means of the RMSEA and the Root Mean Square Standardised Residual (RMR). Each model was identified by constraining the factor variance to unity and all error variances were specified to be uncorrelated.

As a second step, responses to the 27 items comprising the SDCM, VD, BM and MP subscales were jointly subjected to a restricted maximum likelihood confirmatory factor analysis. The measurement model was equivalent to the model tested by Briscoe et al. (2006) and specified that items 1-8 define the SDCM factor, items 9-14 the VD factor, items 15-22 the BM factor and items 23-27 the MP factor. All error variances were specified to be uncorrelated and the model was identified by fixing the factor variances to unity. In accordance with Briscoe et al., the fit of the model to the data was evaluated by means of the likelihood chisquare test, the RMSEA, the Comparative Fit Index (CFI), the Normed Fit Index (NFI) and the Incremental Fit Index (IFI).

Unrestricted factor analysis: As a third step, responses to the 27 items were subjected to an unrestricted maximum likelihood factor analysis, which is one form of common factor analysis (Cudeck, 2000). Although unrestricted, the analysis was conducted in a confirmatory spirit with the aim of identifying sources of misfit in the restricted confirmatory factor analysis (McDonald, 2005).

The scree-plot and the results of a parallel analysis, which are eigenvalues based techniques, were examined to decide the number of factors to retain. In addition, the RMR, the RMSEA and the ECVI, which are residual based techniques, were examined for four-, five- and six-factor solutions. Two principles guided the decision in terms of of how many factors to retain: Firstly, it is generally safer to extract too many factors rather than too few factors (Wood, Tataryn \& Gorsuch, 1995) and secondly, factors are only worth retaining if they are psychologically meaningful and shed light on the sources of misfit in the confirmatory four-factor model. The factors were obliquely rotated to an independent clusters solution (cf. McDonald, 1999) according to the Direct Quartimin criterion. The analyses were done with the Comprehensive Exploratory Factor Analysis computer software (Browne, Cudeck, Tataneni \& Mels, 2004).

Item response theory analysis: Each of the four subscales were analysed by means of the Rasch partial credit model (Wright \& Masters, 1982), which is an extension of Rasch's (1960) simple logistic item response model to items with ordered polytomous response options (Andrich, de Jong \& Sheridan,1997). The Rasch model represents an ideal for unidimensional measurement against which existing and new scales can be judged (Andrich, 1988). The model was used to identify items that do not conform to the requirement of unidimensional measurement and to examine the measurement precision of the Protean and Boundaryless Career Attitude scales.

The partial credit model estimates the location of each item and each person on the same latent trait continuum. An attractive feature of the Rasch model is that if the data fit the requirements of the model, a person's location on the latent trait does not depend on the particular set of items that they are presented with and the location of an item on the latent trait does not depend 
TABLE 1

Residual Based Indicators of the Number of Factors to Retain

\begin{tabular}{lccc}
\hline Model & RMSEA & $\boldsymbol{P}$ (RMSEA $<\mathbf{0 . 0 5 )}$ & ECVI \\
\hline Four factors & $0.059(0.053-0.065)$ & 0.005 & $2.063(1.900-2.244)$ \\
Five factors & $0.054(0.047-0.060)$ & 0.173 & $1.892(1.749-2.053)$ \\
Six factors & $0.046(0.039-0.053)$ & 0.833 & $1.725(1.603-1.864)$ \\
\hline Note: For the RMSEA and the ECVI $90 \%$ confidence intervals are given in parenthesis & & 0.038 \\
\end{tabular}

Note: For the RMSEA and the ECVI $90 \%$ confidence intervals are given in parenthesis

RMSEA, root mean square error of approximation; $P$, probability value; ECVI, excpected cross validation index; RMR, root mean square standardised residual

on the particular group or subset of persons that responded to the item (Wilson, 2005). The model predicts that individuals with higher standings on the latent trait should obtain higher scores on any given item than individuals with lower standings. Similarly, any individual is expected to obtain lower scores on items with higher locations on the latent trait than on items with lower locations (Bond \& Fox, 2001).

The item and person parameters were estimated with the Rumm 2020 computer programme (Andrich, Sheridan, \& Luo, 2007). The estimated parameters are used to calculate expected item scores for each person. The expected item scores can then be compared with the observed scores. The programme employs several fit statistics, of which the Pearson chi-square and standardised residual statistics are reported here. A standardised residual > 2.5 indicates that the item does not discriminate as well between persons with different locations on the latent trait as expected. In contrast, a standardised residual $<-2.5$ indicates that the item discriminates more sharply than expected.

A statistically significant chi-square for an item indicates that individuals with different trait estimates find the item differentially difficult to endorse, which violates the requirement that the location of an item should be independent of the particular group of persons who responded to the item (Andrich, 1988). To protect against the probability of Type I errors, the level of significance for each individual chi-square test was set as follows:

- $\operatorname{SDCM}(8$ items), $\alpha=0.05 / 8=0.006$

- VD (6 items), $\alpha=0.05 / 6=0.008$

- $\operatorname{BM}(9$ items $), \alpha=0.05 / 9=0.006$

- $\mathrm{MP}(5$ items), $\alpha=0.05 / 5=0.01$.

The overall fit of the items is summarised in a total item chisquare.

Unlike classical test theory methods, which assumes that the precision with which a test measures is constant across the underlying trait continuum, Rasch models acknowledge that tests or scales operate differently for individuals with different trait levels (Wilson, 2005). The test information curve may be used to identify the areas of the latent trait in which the test or scale operates most efficiently and in which areas it operates less efficiently. The trait estimates of individuals who are located at a point where the test or scale provides much information are measured with more precision than the trait estimates of an individual located at a point where the test or scale provides little information (Embretson \& Reise, 2000).

Rasch analyses produce a summary index of measurement precision, namely the Person Separation Reliability Index (Wright \& Masters, 1982), which is similar in interpretation to Cronbach's coefficient alpha. Rasch analyses provide a direct estimate of each person's modeled error variance, which may be averaged to obtain a mean square measurement error (MSE). The MSE is subtracted from the total variance of the person measures to obtain an estimate of the true variance. The ratio of the true variance to the total variance gives the Person Separation Reliability Index (Wright \& Masters, 1982).

\section{RESULTS}

\section{Confirmatory factor analysis}

The results of the four separate Spearman analyses showed that the SDCM $($ RMSEA $=0.063 ; \mathrm{RMR}=0.040)$ and MP $($ RMSEA $=$
0.063; $\mathrm{RMR}=0.021)$ subscales could reasonably be regarded as unidimensional. However, the VD (RMSEA = 0.146; RMR = $0.078)$ and BM (RMSEA $=0.132 ; \mathrm{RMR}=0.059)$ subscales did not fit the unidimensional model very well.

Next, responses to the entire set of 27 items were subjected to a maximum likelihood confirmatory factor analysis. The likelihood chi-square statistic showed that the model did not fit the data from a statistical perspective, $\chi^{2}(318)=892.067, p$ $<0.001$. Similarly, the CFI (0.860), NFI (0.800), IFI (0.861) and RMR (0.071) suggested less than satisfactory fit from a practical perspective. The RMSEA value of 0.065 fell on the boundary of $\mathrm{Hu}$ and Bentler's (1999) criterion for satisfactory fit (RMSEA < 0.06). Overall, the fit of the four-factor confirmatory model was unsatisfactory. Inspection of the normalised residual covariances demonstrated that on average items 1 (SDCM), 15 (BM), 9 (VD), 22 (BM), 12 (VD), 8 (SDCM) and 14 (VD) contributed most toward the unsatisfactory fit of the full confirmatory factor analysis model. It is noteworthy that five of the six problematic items were from the VD and BM subscales which demonstrated the poorest fit with the Spearman model when analysed separately.

\section{Unrestricted factor analysis}

The data were subjected to an unrestricted maximum likelihood factor analysis to identify possible sources of misfit in the confirmatory factor analysis model (cf. Hoyle, 2000; McDonald, 2005). The scree-plot and parallel analysis suggested five factors. Table 1 contains values of the RMSEA, ECVI and RMR for four-, five- and six-factor solutions. These values also pointed toward the retention of five factors.

The Direct Quartimin rotated five-factor solution ${ }^{1}$ demonstrates that the first three factors represent the BM, MP and SDCM subscales, respectively (see Table 2). However, the fourth and fifth factors represent a split of the VD scale and are labeled VD1 and VD2, respectively. Items 9, 10, 11 and 13 defined factor 4, whereas items 12, 13 and 14 defined factor 5 . Items 1,8 and 15 did not have loadings $>0.3$ on their expected factors.

The correlations between the factors were low and ranged from -0.020 (SDCM and MP) to 0.271 (SDCM and VD2) (see Table 3). The correlation between factors VD1 and VD2 was 0.204, suggesting that the factors measure two psychologically distinct constructs.

\section{Rasch item response theory analysis}

The overall fit and person separation reliability indices are summarised in Table 4. Only the VD scale showed an acceptable overall fit, but the Person Separation Reliability Index for this scale was relatively low (PSRI $=0.678$ ). The corresponding Cronbach alpha coefficient was 0.654 . Low reliability reduces the power to detect misfit (Andrich, 1988), which possibly accounts for the observed good fit of the VD scale.

The individual item fit statistics highlighted five poorly fitting items: items 1 and 8 (SDCM scale), items 15 and 21 (BM scale) and item 23 (MP scale). These items discriminated weaker than predicted by the Rasch model. Removing these items from the analyses resulted in improved fit and person separation

1.We also rotated a four-factor solution, which on the surface appeared to correspond with the four theoretical constructs. However, there were several items with weak loadings on their intended factors and several items with large secondary loadings on unintended constructs. 
TABLE 2

Oblique Direct Quartimin Rotated Five-Factor Solution

\begin{tabular}{|c|c|c|c|c|c|c|}
\hline \multirow{2}{*}{ Item } & & \multicolumn{5}{|c|}{ Factor } \\
\hline & & BM & MP & SDCM & VD1 & VD2 \\
\hline 1. & $\begin{array}{l}\text { When development opportunities have not been offered by my company, I have sought } \\
\text { them out on my own }\end{array}$ & 0.200 & -0.144 & 0.293 & 0.075 & -0.026 \\
\hline 2. & I am responsible for my success or failure in my career & 0.031 & 0.078 & 0.537 & 0.069 & -0.114 \\
\hline 3. & Overall, I have a very independent, self-directed career & 0.028 & -0.045 & 0.517 & -0.036 & 0.096 \\
\hline 4. & Freedom to choose my own career path is one of my most important values & 0.053 & -0.038 & 0.489 & -0.001 & 0.109 \\
\hline 5. & I am in charge of my own career & -0.050 & 0.018 & 0.769 & -0.016 & -0.018 \\
\hline 6. & Ultimately, I depend on myself to move my career forward & 0.034 & -0.088 & 0.596 & -0.015 & 0.071 \\
\hline 7. & Where my career is concerned, I am very much 'my own person' & -0.022 & 0.071 & 0.535 & 0.028 & 0.248 \\
\hline 8. & In the past, I have relied more on myself than on others to find a new job when necessary & 0.021 & -0.092 & 0.133 & 0.181 & 0.163 \\
\hline 9. & $\begin{array}{l}\text { I navigate my own career, based on my personal priorities, as opposed to my employer's } \\
\text { priorities }\end{array}$ & 0.092 & 0.056 & 0.174 & -0.021 & 0.595 \\
\hline 10. & It does not matter much to me how other people evaluate the choices I make in my career & -0.060 & -0.063 & 0.050 & 0.066 & 0.476 \\
\hline 11. & $\begin{array}{l}\text { What is most important to me is how I feel about my career success, not how other people } \\
\text { feel about it }\end{array}$ & 0.000 & -0.041 & -0.003 & 0.177 & 0.35 \\
\hline 12. & $\begin{array}{l}\text { I will follow my own conscience if my company asks me to do something that goes against } \\
\text { my values }\end{array}$ & -0.042 & -0.030 & 0.003 & 0.774 & -0.033 \\
\hline 13. & $\begin{array}{l}\text { What I think about what is right in my career is more important to me than what my } \\
\text { company thinks }\end{array}$ & 0.009 & 0.019 & 0.037 & 0.425 & 0.385 \\
\hline 14. & $\begin{array}{l}\text { In the past I have sided with my own values when the company has asked me to do } \\
\text { something I do not agree with }\end{array}$ & 0.110 & 0.009 & -0.066 & 0.568 & 0.054 \\
\hline 15. & I seek job assignments that allow me to learn something new & 0.258 & 0.031 & 0.143 & 0.241 & 0.001 \\
\hline 16. & I would enjoy working on projects with people across many organisations & 0.619 & -0.091 & 0.010 & -0.019 & 0.080 \\
\hline 17. & I enjoy job assignments that require me to work outside of the organisation & 0.788 & -0.021 & -0.159 & -0.069 & 0.133 \\
\hline 18. & I like tasks at work that require me to work beyond my own department & 0.705 & -0.022 & 0.016 & 0.045 & -0.034 \\
\hline 19. & I enjoy working with people outside of my organisation & 0.867 & 0.030 & 0.015 & 0.015 & -0.045 \\
\hline 20. & I enjoy jobs that require me to interact with people in many different organisations & 0.811 & 0.055 & 0.089 & -0.003 & -0.059 \\
\hline 21. & I have sought opportunities in the past that allow me to work outside the organisation & 0.559 & -0.115 & -0.085 & 0.066 & 0.083 \\
\hline 22. & I am energised in new experiences and situations & 0.485 & -0.080 & 0.282 & 0.092 & -0.101 \\
\hline 23. & I like the predictability that comes with working continuously for the same organisation & 0.037 & 0.555 & -0.001 & 0.092 & 0.033 \\
\hline 24. & I would feel lost if I could not work for my current organisation & -0.018 & 0.724 & 0.009 & -0.084 & 0.078 \\
\hline 25. & I prefer to stay in a company I am familiar with rather than look for employment elsewhere & 0.009 & 0.881 & 0.006 & 0.058 & -0.029 \\
\hline 26. & $\begin{array}{l}\text { If my organisation offered lifetime employment, I would never desire to seek work in other } \\
\text { organisations }\end{array}$ & -0.008 & 0.895 & 0.025 & -0.031 & -0.013 \\
\hline 27. & In my ideal career I would only work for one organisation & -0.008 & 0.749 & -0.070 & -0.017 & 0.002 \\
\hline
\end{tabular}

Note: Factor loadings $>0.300$ are printed in bold

BM, boundaryless mindset; MP, mobility preference; SDCM, self-directed career management; VD, values driven

TABLE 3

Factor Correlations of the Five-Factor Solution

\begin{tabular}{lccccc}
\hline & BM & MP & SDCM & VD1 & VD2 \\
\hline BM & 1.000 & - & - & - & - \\
MP & 0.248 & 1.000 & - & - & - \\
SDCM & 0.156 & -0.020 & 1.000 & - & - \\
VD1 & 0.198 & 0.208 & 0.206 & 1.000 & - \\
VD2 & 0.177 & 0.021 & 0.271 & 0.204 & 1.000 \\
\hline
\end{tabular}

BM, boundaryless mindset; MP, mobility preference; SDCM, self-directed career management; VD, values driven

reliability for the SDCM, BM and MP subscales. The overall fit of the reduced SDCM, BM and MP subscales is also reported in Table 5. Table 5 also shows that the PSRI of the three scales were satisfactory and ranged from $0.792(\mathrm{SDCM})$ to $0.882(\mathrm{MP})$. These values corresponded very closely with the values of Cronbach's coefficient alpha.

Against the background of the results of the unrestricted factor analysis and the unsatisfactory person separation reliability of the VD scale, the Rasch residuals of the VD scale were subjected to a principal components analysis, which produced a first component that contrasted items 9, 10 and 11 with items 12 and 14. This component accounted for approximately $13 \%$ of the variance in the Rasch residuals, when in theory there should be no discernable structure in the Rasch residuals if the data fits the model (Smith, 2002).

Figures 1-4 demonstrate that the SDCM and BM subscales (and to a lesser extent the VD scale) provided most of their psychometric information at the lower ends of the person distributions where 
TABLE 4

\begin{tabular}{|c|c|c|c|c|c|c|}
\hline$\overline{\text { Scale }}$ & Total item $\chi^{2}$ & $\overline{d f}$ & $\bar{p}$ & $\begin{array}{l}\text { PSRI } \\
\end{array}$ & Cronbach's $\alpha$ & Items deleted \\
\hline$\overline{\mathrm{SDCM}}$ & 124.228 & 48 & $<0.000001$ & 0.769 & 0.735 & - \\
\hline $\mathrm{SDCM}^{*}$ & 57.901 & 36 & 0.012 & 0.792 & 0.766 & 1 and 8 \\
\hline VD & 48.987 & 36 & 0.073 & 0.678 & 0.654 & - \\
\hline BM & 142.633 & 48 & $<0.00001$ & 0.874 & 0.863 & - \\
\hline $\mathrm{BM}^{*}$ & 55.549 & 36 & 0.020 & 0.880 & 0.869 & 15 and 21 \\
\hline MP & 90.408 & 30 & $<0.00001$ & 0.856 & 0.873 & - \\
\hline$M P^{*}$ & 34.194 & 24 & 0.081 & 0.882 & 0.887 & 23 \\
\hline
\end{tabular}

Note: Asterisks indicate reduced scales in which misfitting items are deleted

$d f$, degrees of freedom; $p$, probability value; PSRI, person separation reliability index

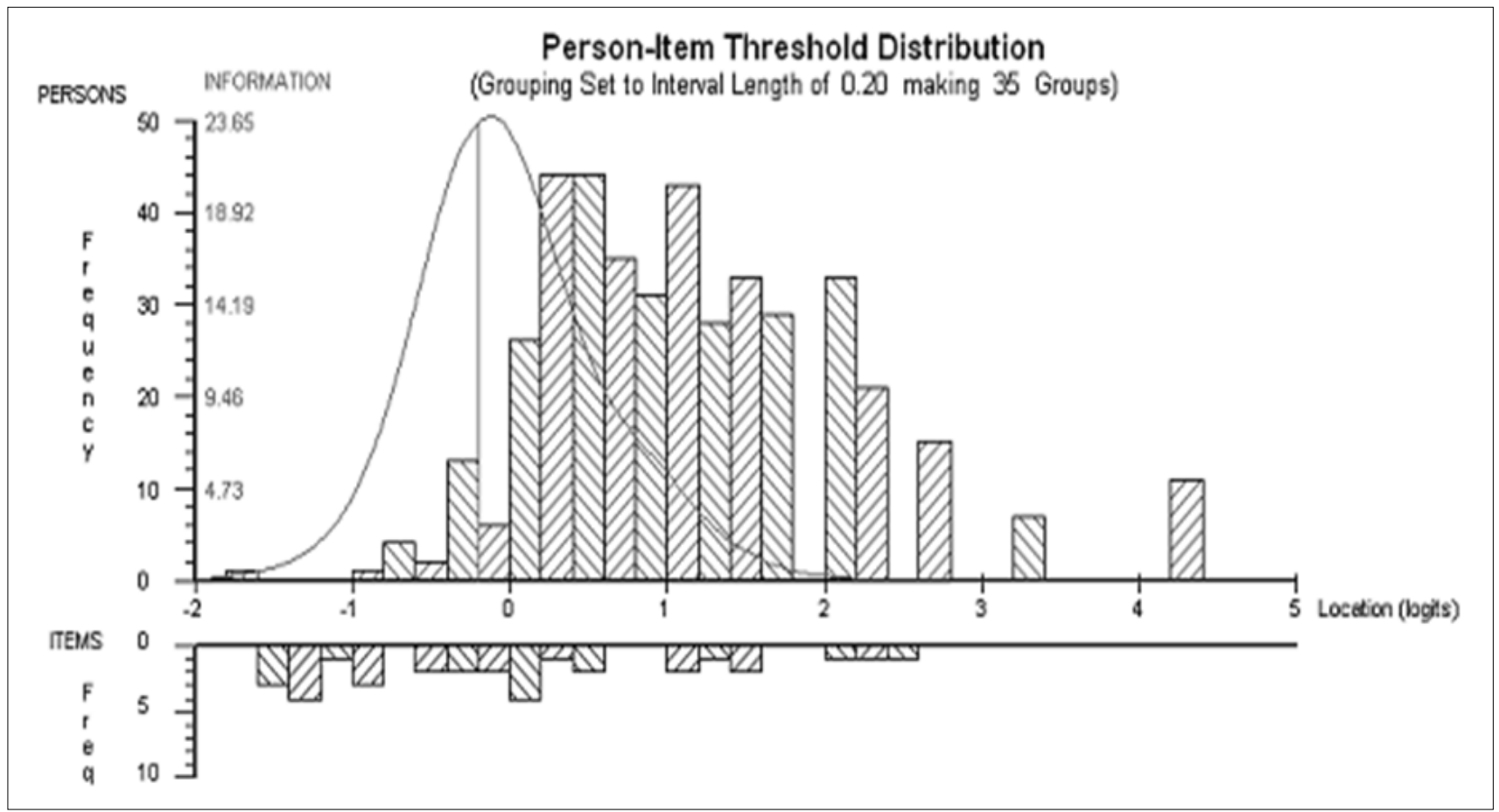

FIGURE 1

Person-item threshold distribution and information function for the Self-Directed Career Management Scale

relatively few persons were located. A comparison of the person distributions and the category threshold distributions shows that the present group of participants found the items of the SDCM, VD and BM scales too easy to endorse.

In contrast, the test information curve of the MP scale and the comparison of the person distributions and category threshold distributions, demonstrates that the locations of the items match the central location of the persons (see Figure 3). This scale operates most effectively in the middle range of the person distribution, but operates less efficiently at the extreme upper and lower ends of the latent trait.

\section{DISCUSSION}

Briscoe et al. (2006) recently introduced the Protean and Boundaryless Career Attitude scales to operationalise the protean and boundaryless career attitude constructs. The Protean Attitude is represented by the Self Directed Career Management (SDCM) and Values Driven (VD) subscales, whereas the Boundaryless Attitude is represented by the Mobility Preference (MP) and Boundaryless Mindset (BM) subscales. The present study aimed to shed light on three unanswered questions in terms of the four subscales (Briscoe et al., 2006). The first relates to the dimensionality of the four subscales, the second relates to the quality of the individual items and the third relates to the measurement precision across the latent trait continuum of each subscale.

The most important findings may be summarised as follows:

- The SDCM, BM and MP subscales measure essentially unidimensional latent traits, but the VD scale appears to measure two latent traits.

- Five of the 27 items appear to function relatively unsatisfactory and these items can also be seen to function relatively unsatisfactory in the Briscoe et al. (2006) study.

- The SDCM, VD and BM subscales measure with greater precision at the lower ends of their respective latent traits than at the upper ends. In the paragraphs that follow the theoretical and practical implications of these findings are discussed in more detail.

The dimensionality of the self-directed career management, values driven, boundaryless mindset and mobility preference subscales

Confirmatory factor analysis yielded an unsatisfactory fit between the postulated four-factor model and the observed data and demonstrated that the BM and VD scales were not unidimensional. Unrestricted maximum likelihood factor analysis showed that five factors were necessary to provide a satisfactory account of the covariances of the 27 items. 


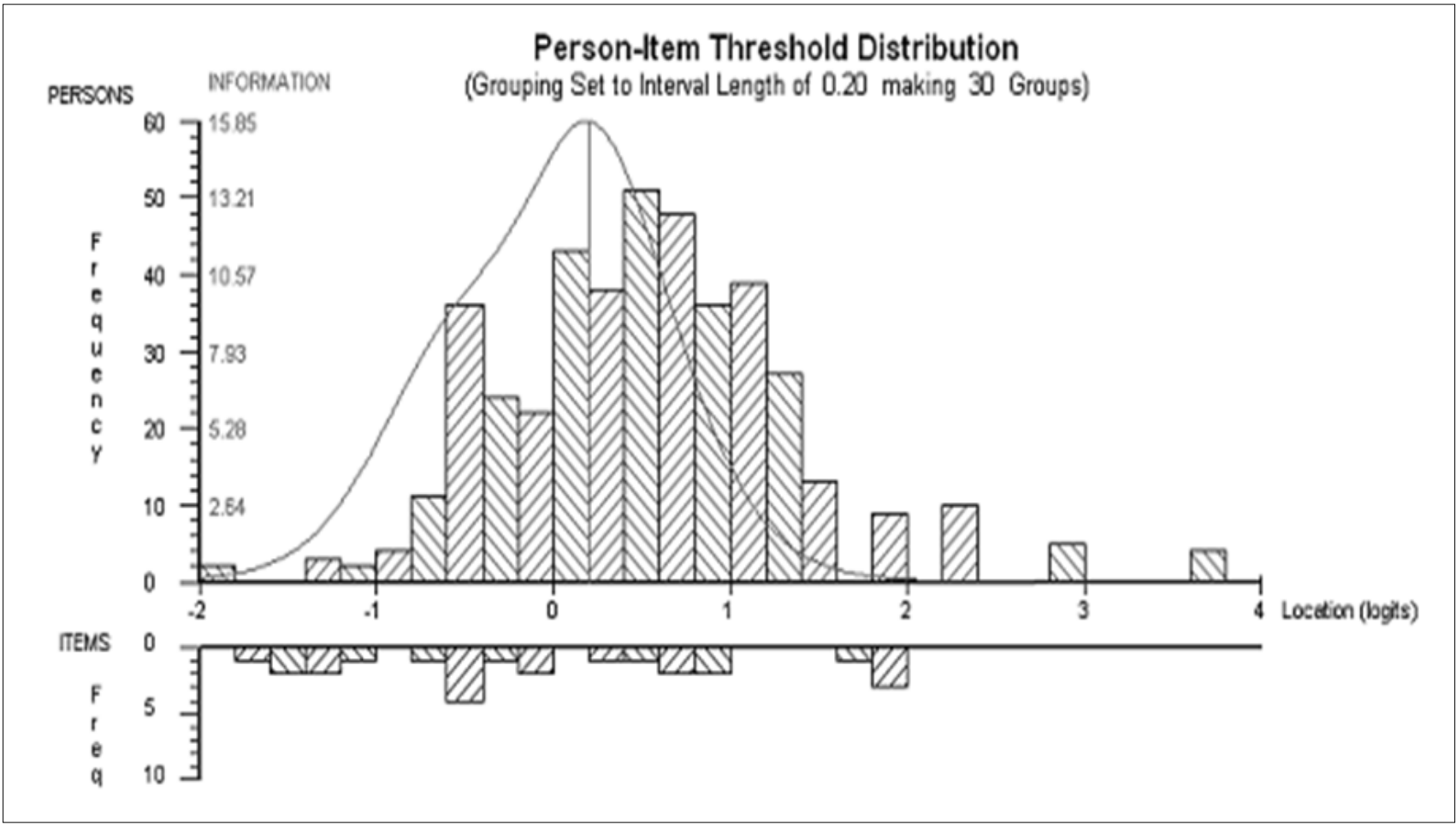

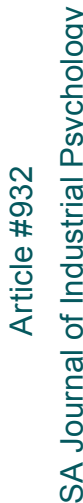

nd information function for the Values Driven Scale

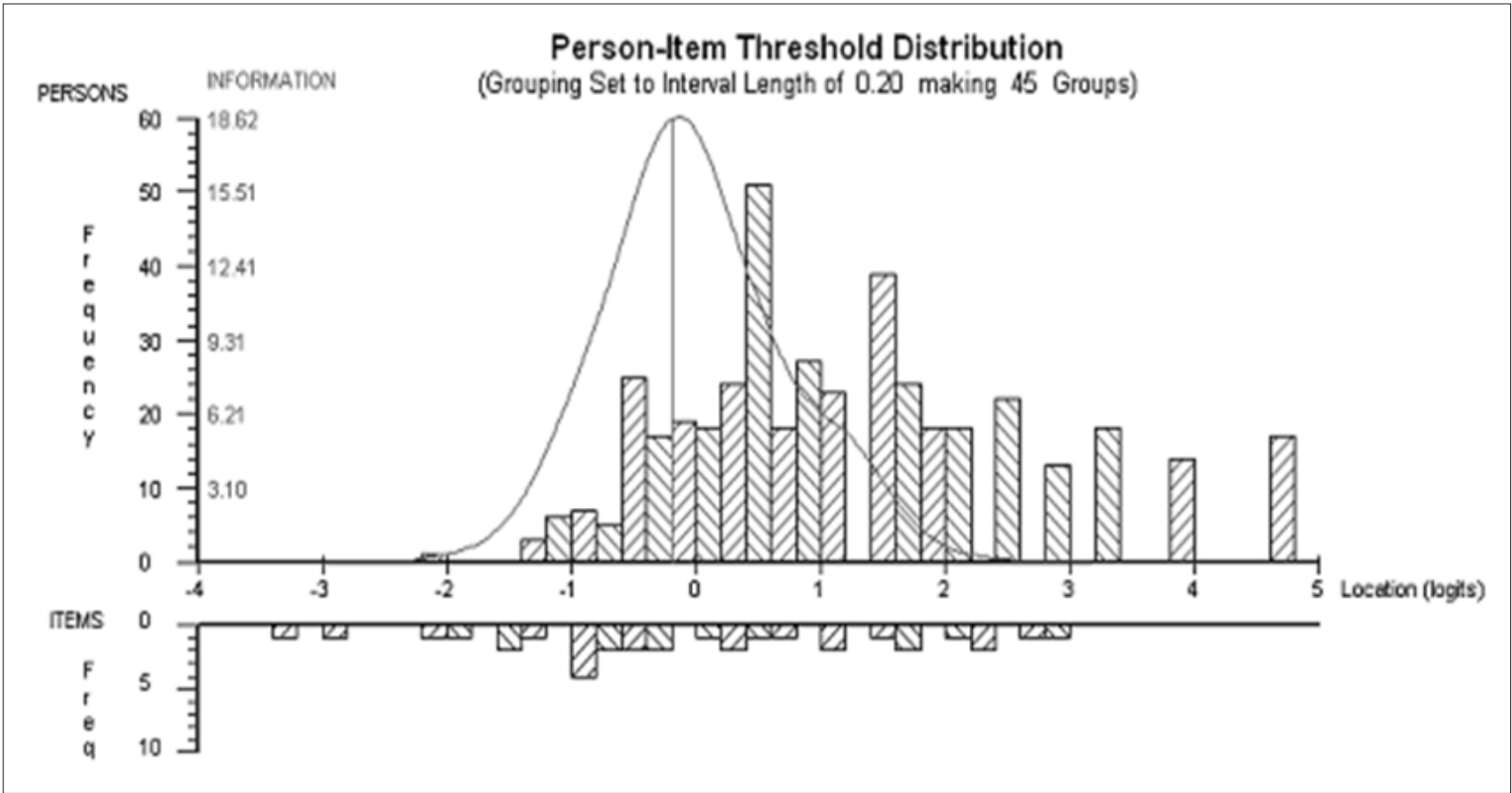

FIGURE 3

Person-item threshold distribution and information function for the Boundaryless Mindset Scale

The five-factor model provides support for the construct validity of the SDCM, BM and MP subscales. Each of these factors corresponds strongly with Briscoe et al.'s (2006) scoring key and, with a few minor exceptions, the items of each scale measure an essentially unidimensional trait. It appears safe to conclude that these three factors largely accord with their corresponding theoretical constructs.

However, the six items of the VD scale appear to measure two psychologically distinct latent traits. High scores on the first factor (VD1), which is defined by items 12, 13 and 14, appear to indicate a strong sense of morally acceptable behavior. In addition, high scores appear to indicate that individuals have the self-perceived ability to withstand pressure from the organisation when they are required to do something they deem to be wrong by their own standards (for instance item 12: 'I'll follow my own conscience if my company asks me to do something that goes against my values'). From this perspective, being values driven implies that individuals have strong core beliefs that they use as normative standards to guide their behavior. 


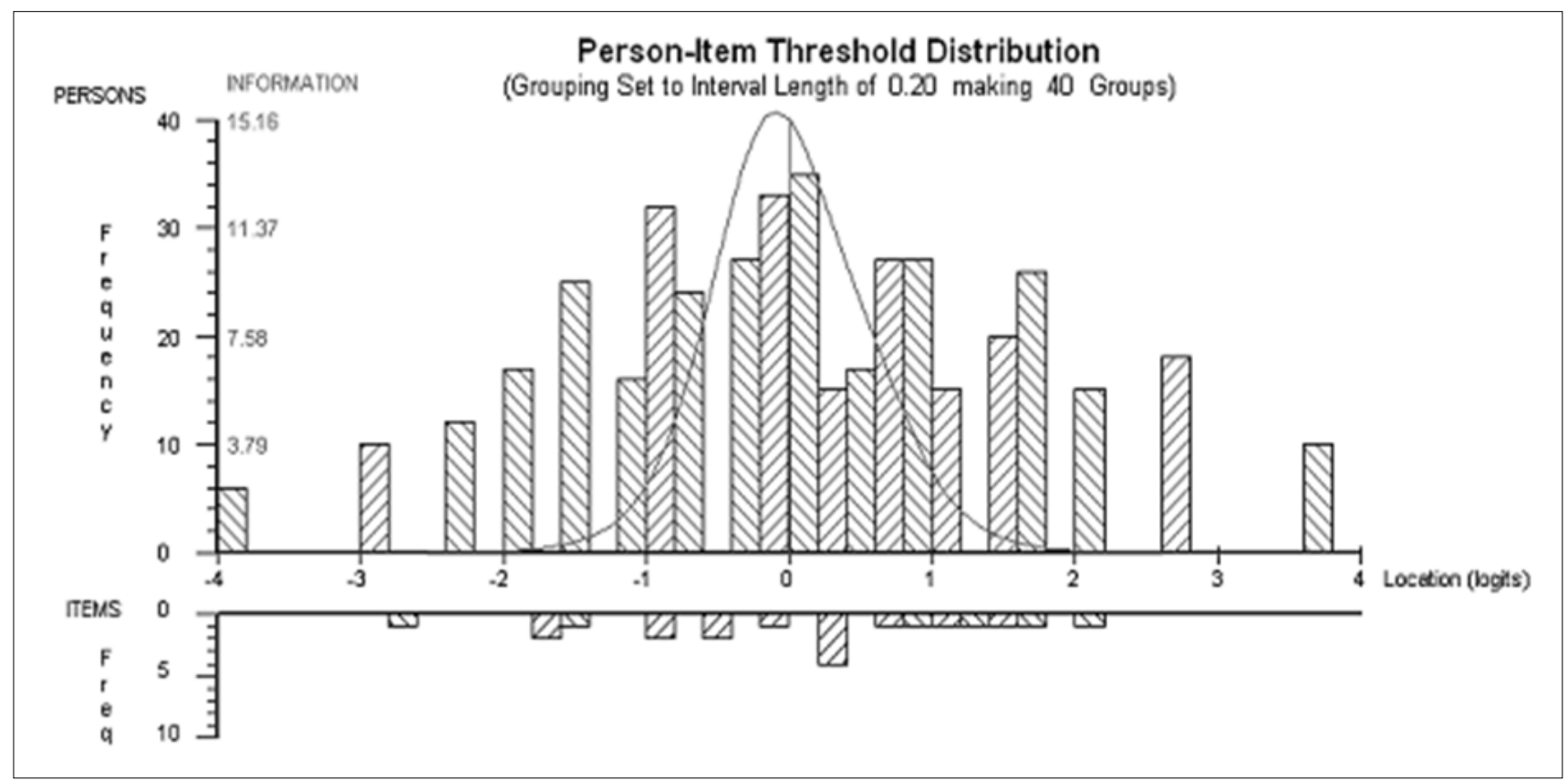

FIGURE 4

Person-item threshold distribution and information function for the Mobility Preference Scale

Factor VD2 appears to reflect the agentic or motivational aspect of being values driven. Items 9, 10, 11 and 13 focus on the pursuit of the individual's own career needs and goals rather than the needs and goals of the organisation, or of other people. High scores reflect personal autonomy, individual agency and perhaps a clear sense of identity. Individuals with high scores define career success on their own terms rather than those of the organisation or other external parties and pursue their own career related needs.

These results demonstrate that the interpretation of scores on the VD subscale can be interpreted with less confidence than scores on the SDCM, BM and MP subscales. For instance, individuals may obtain an average score on the VD scale firstly because they are high on VD1 and low on VD2, secondly because they are low on VD1 and high on VD2, or thirdly because they are average on both VD1 and VD2. These ambiguities can be resolved by developing separate VD1 and VD2 scales, or by improving the homogeneity of the VD items so that they more closely constitute a unidimensional scale.

A disadvantage of the five-factor model is that it diverges slightly from the underlying theoretical model, which specifies four factors and could be seen to work against the accumulation of research results. However, it may be more harmful to ignore the multidimensionality of the VD scale because 'Scales that correspond poorly with the constructs they are intended to represent cannot provide the basis for clear answers to empirical questions' (McGrath, 2005, p. 113).

\section{A cross-cultural perspective on the dimensionality of the values driven subscale}

It is not clear whether the split of the VD scale into two factors will be observed in other countries or cultures. Briscoe and Hall (2006) and Briscoe et al. (2006) paint a picture of high VD scorers as persons who strive towards independence, autonomy and individual agency. They may be seen as persons who have a clear sense of identity and who succeed in implementing their self-concepts in their career related choices and decisions. This is consistent with an individualistic or independence worldview, where autonomy, individual agency and the active pursuit of one's personal goals and priorities are seen as a sign of maturity and good adjustment (cf. Cross \& Markus, 1999; Sue \& Constantine, 2003). This worldview is typically endorsed by people from North America and Europe.

However, in many other societies, greater emphasis is placed on community than on individuality and autonomy. African societies may be said to endorse a collectivistic or an interdependence worldview. In these societies, personal choice and one's personal wishes, desires, interests and abilities in career decisions may be seen as of lesser importance than how one's career decisions contribute to the goals and the wellbeing of the community (De Bruin \& De Bruin, 2006). Indeed, as Cook, Heppner and O'Brien (2002) pointed out, individuals who endorse a collectivistic or interdependence point of view may see the quality of relationships with others, the fulfilling of social obligations and attending to the needs of others as more important than personal happiness, autonomy, freedom of choice and self-determination. This does not mean that these individuals do not have personal aspirations, dreams, interests and values. It probably does mean, however, that these aspirations, dreams and interests need to be balanced with and possibly be placed in a position of lesser importance than the aspirations, dreams and interests of the community.

Against this background it appears likely that items 9, 10 and 11 of the VD scale, which focus on individuals putting their needs above that of the organisation and other people, can differ in psychological meanings for individuals from individualistic/ independence and collectivistic/interdependence cultures. For instance, a highly values driven individual from an individualistic/independence culture may find it easy to agree with item 11 ('What's most important to me is how I feel about my career success, not how other people feel about it'). In contrast, a highly values driven individual from a collectivistic/ interdependence culture may find it difficult to agree with item 11 because of a cultural norm that dictates that the opinions of other people are important and need to be respected. It is possible that such differences in interpretation may have contributed toward the observed multidimensionality of the VD scale.

\section{The quality of the individual items}

Overall, the results of the factor and Rasch analyses demonstrate that the majority of items function satisfactorily. However, items 
$1,8,15,21$ and 23 elicited unexpected responses conditional on a person's standing on the latent trait.

In the Briscoe et al. (2006) standardisation study, items 1 and 8 had the weakest and third weakest loadings on the SDCM component, item 23 had the second weakest loading on the MP component and items 15 and 21 had the weakest and third weakest loadings on the BM component. Hence, relative to the entire set of 27 items, items 1, 8, 15, 21 and 23 also were weak indicators of their respective constructs in the Briscoe et al. (2006) standardisation study ${ }^{2}$

Items 1, 8 (SDCM scale) and item 21 (BM scale) concern career related attitudes in an individual's past, whereas the majority of the items in the entire set concern an individual's present career related attitudes. As emphasised by Briscoe et al. (2006), the SDCM and BM subscales measure career related attitudes rather than traits. Attitudes may change over time. Hence, it is possible, for instance, to find an individual who previously might have held a traditional attitude in regard to his or her career development to hold a protean and/or boundaryless attitude in the present. This may explain why items 1,8 and 21 were identified by the Rasch model as eliciting unexpected responses. It appears undesirable to mix in the same scale items that enquire about present and past attitudes and behaviors. The SDCM and BM subscales may be improved by replacing items 1,8 and 21 with items that focus on present rather than past attitudes and behaviors.

Item 15 is the only one of the BM set that does not explicitly refer to experiences or contacts across departmental/organisational boundaries. Individuals with low standings on the trait may endorse this item just because they like learning new things, even though they have no desire to implement what they learn outside the departmental/organisational boundaries of their current job. From this perspective some individuals may have low standings on the BM latent trait and yet obtain high scores on item 15.

There is no plausible explanation for the misfit of item 23. Visual inspection showed that the discrepancies between the Rasch derived empirical and theoretical item characteristic curves for item 23 were small, except at the very low and high ends of the latent trait. Hence, the fit of item 23 appears to be satisfactory from a practical measurement perspective.

\section{The measurement precision of the subscales across the latent trait continuum}

Three of the four subscales, namely SDCM, VD and BM, provide most of their psychometric information at the lower end of the person distributions. Hence, relatively precise measures of individuals with low standings on the three latent traits are obtained, but relatively imprecise measures of individuals with high standings are obtained (Wright \& Stone, 1979). Figures 1, 2 and 4 show that the items are poorly targeted, with the majority of persons located higher on the latent trait continuum than the item category thresholds. This does not constitute a major problem if researchers wish to use the scales among individuals who are expected to obtain low scores on the SDCM, VD and MP subscales. These subscales, however, may be more useful as general measures that can be used with individuals across the entire trait ranges of the protean and boundaryless career concepts. Moreover, the relations of these three subscales with other variables may be attenuated in groups with a large proportion of high scoring individuals. Another undesirable consequence is that the subscales may fail to detect interindividual differences or intra-individual changes over time among individuals with high scores. This may restrict the general

2.In the Briscoe et al. (2006) standardisation study the component loadings of the three items were 0.348 for item $1,0.414$ for item 8 and 0.563 for item 15 . It should be kept in mind that these loadings are inflated due to the use of the principal components model rather than the common factor model. utility of the scales and / or cast unjustified doubt on the construct validity of the scales. The scales may be improved by including additional items that have higher affective intensity or, put differently, items that provide more psychometric information at the upper ends of the traits. This should increase the ranges over which the scales provide precise person measures (Wright \& Stone, 1979).

\section{Conclusion}

Limitations and recommendations

The principal limitation of the study is that the factor and Rasch analyses are not replicated on an independent sample, which may raise questions about the generality of the results. In particular, readers may question whether items 1, 8, 15, 21 and 23 also function poorly in other samples and whether the split of the Values Driven factor can be observed in other samples.

The items found to function poorly in this study can also be seen to function relatively poorly in the Briscoe et al. (2006) study. Moreover, semantical and conceptual analyses provide a plausible substantive explanation for the poor fit of the four weakest items. Also, semantical and conceptual analyses provide a plausible explanation for the split of the VD factor and its low reliability. Although not immediately explicit, close examination of Briscoe et al.'s exploratory factor analysis of the VD and SDCM items also shows that the items of the VD scale do not constitute a homogenous unidimensional scale. However, only subsequent studies will confirm the replicability of these findings.

A second limitation is that the study focuses only on the internal psychometric properties of the scales. A deeper understanding of the psychological meaning of the scales will be obtained by studying their relations with external variables.

The construction of the Protean and Boundaryless Career Attitude Scales constitute a potentially important advancement, which may stimulate empirical research and theory development on adult career development. The present study highlighted some weaknesses in the subscales which might inhibit such efforts. The present study also revealed the sources of the weaknesses and these can and should be corrected. In this regard the following recommendations are made:

1. Improve the homogeneity of the items that constitute the Values Driven subscale, or, if researchers deem it important to include both the normative and agentic aspects of being values driven in the Protean Attitudes Scale, it will be necessary to separately develop these subscales.

2. Write items for the SDCM, VD and BM subscales that are better targeted at individuals who measure high in protean and boundaryless attitudes (this will also serve to improve the reliabilities of the subscales).

3. Replace items that enquire about individuals' past career behaviours and attitudes with items that focus on current career behaviors and attitudes.

\section{Implications for future research}

Future research may also focus more explicitly on the crosscultural equivalence of the Protean and Boundaryless Career Attitude Scales across cultures by investigating aspects such construct equivalence and differential item functioning. These efforts are bound to lead to a deeper understanding of the constructs and shed light on the conditions and contexts where the protean and boundaryless career concepts are most useful.

\section{ACKNOWLEDGEMENTS}

I am grateful toward the following people who commented on a draft version of this manuscript: Johann Schepers, Freddie Crous, Koos Uys, Gert Roodt, Marcel Harper and Karina de Bruin. 


\section{REFERENCES}

Anderson, J.C., \& Gerbing, D.W. (1982). Some methods for respecifying measurement models to obtain unidimensional construct measurement. Journal of Marketing Research, 19, 453-460.

Andrich, D. (1988). Rasch models for measurement. Thousand Oaks: Sage.

Andrich, D., de Jong, J.H.A.L., \& Sheridan, B.E. (1997). Diagnostic opportunities with the Rasch model for ordered response categories. In J. Rost \& R. Langeheine (Eds.), Applications of latent trait and latent class models in the social sciences (pp. 59-70). New York: Waxmann.

Andrich, D., Sheridan, B., \& Luo, G. (2007). Rumm 2020: Rasch Unidimensional Measurement Models, Version 4.1 [Computer programme]. Perth: Rumm Laboratory.

Arthur, M.B. (1994). The boundaryless career: A new perspective for organizational inquiry. Journal of Organizational Behavior, 15, 295-306.

Arthur, M.B., Khapova, S.N., \& Wilderom, C.P.M. (2005). Career success in a boundaryless career world. Journal of Organizational Behavior, 26, 177-202.

Baruch, Y. (2006). Career development in organizations and beyond: Balancing traditional and contemporary viewpoints. Human Resource Management Review, 16, 125138.

Baruch, Y., \& Hall, D.T. (2004). The academic career: A model for future careers in other sectors? Journal of Vocational Behavior, 64 , 241-262.

Bond, T.G., \& Fox, C.M. (2001). Applying the Rasch model: Fundamental measurement in the human sciences. Mahwah: Erlbaum.

Briscoe, J.P., \& Hall, D.T. (2006). The interplay of boundaryless and protean careers: Combinations and implications. Journal of Vocational Behavior, 4-18.

Briscoe, J.P., Hall, D.T., \& DeMuth, R.L.F. (2006). Protean and boundaryless careers: An empirical investigation. Journal of Vocational Behavior, 69, 30-47.

Browne, M.W., Cudeck, R., Tateneni, K., \& Mels, G. (2004). CEFA: Comprehensive exploratory factor analysis, Version 2.00 [Computer software and manual]. Retrieved from http:// quantrm2.psy.ohio-state.edu/browne/

Cook, E.P., Heppner, M.J., \& O’Brien, K.M. (2002). Career development of women of color and white women: Assumptions, conceptualization, and interventions form an ecological perspective. Career Development Quarterly, 50, 291-305.

Cross, S.E., \& Markus, H.R. (1999). The cultural constitution of personality. In L.A. Pervin \& O.P. John (Eds.), Handbook of personality: Theory and research (2nd ed., pp. 378-396). New York: Guilford.

Cudeck, R. (2000). Exploratory factor analysis. In H.E.A. Tinsley \& S.D. Brown (Eds.), Handbook of applied multivariate statistics and mathematical modeling (pp. 265-296). San Diego: Academic Press.

De Bruin, G.P., \& De Bruin, K. (2006). Career assessment. In G.B. Stead \& M.B. Watson (Eds.), Career psychology in the South African context (2nd edn., pp. 129-136). Pretoria: Van Schaik.

Embretson, S.E., \& Reise, S.P. (2000). Item response theory for psychologists. Mahwah: Erlbaum.

Gorsuch, R.L. (1997). Exploratory factor analysis: Its role in item analysis. Journal of Personality Assessment, 68, 532560.

Granrose, C.S., \& Baccili, P.A. (2006). Do psychological contracts include boundaryless or protean careers? Career Development International, 11, 163-182.

Hall, D.T. (1976). Careers in organizations. Glenview: Scott, Foresman.
Hall, D.T. (2002). Protean careers in and out of organizations. Thousand Oaks: Sage.

Hall, D.T. (2004). The protean career: A quarter-century journey. Journal of Vocational Behavior, 65, 1-13.

Hall, D.T., \& Chandler, D.E. (2005). Psychological success: When the career is a calling. Journal of Organizational Behavior, 26, $155-176$.

Hall, D.T., \& Mirvis, P.H. (1996). The new protean career: Psychological success and the path with a heart. In D.T. Hall (Ed.), The career is dead, long live the career: A relational approach to careers (pp. 15-45). San Francisco: Jossey Bass.

Hansen, L.S. (1997). Integrative Life Planning: Critical tasks for career development and changing life patterns. San Francisco: Jossey-Bass.

Hoyle, R.H. (2000). Confirmatory factor analysis. In H.E.A. Tinsley \& S.D. Brown (Eds.), Handbook of applied multivariate statistics and mathematical modeling (pp. 466-497). San Diego: Academic Press.

Hu, L., \& Bentler, P.M. (1999). Cutoff criteria for fit indexes in covariance structure analysis: Conventional criteria versus new alternatives. Structural Equation Modeling, 6, $1-55$.

Inkson, K. (2006). Protean and boundaryless careers as metaphors. Journal of Vocational Behavior, 69, 48-63.

McDonald, R.P. (1999). Test theory: A unified treatment. Mahwah: Erlbaum.

McDonald, R.P. (2005). Semiconfirmatory factory analysis: The example of anxiety and depression. Structural Equation Modeling, 12, 163-172.

McGrath, R.E. (2005). Conceptual complexity and construct validity. Journal of Personality Assessment, 85, 112-124.

O'Connor, B. P. (2000). SPSS and SAS programs for determining the number of components using parallel analysis and Velicer's MAP test. Behavior Research Methods, Instrumentation, and Computers, 32, 396-402.

Rasch, G. (1960). Probabilistic models for some intelligence and attainment tests. Copenhagen: Denmarks Paedagogiske Institut.

Smith, E.V., Jr. (2002). Understanding Rasch measurement: Detecting and evaluating the impact of multidimenstionality using item fit statistics and principal component analysis of residuals. Journal of Applied Measurement, 3, 205231.

Sue, D.W., \& Constantine, M.G. (2003). Optimal human functioning in people of color in the United States. In W.B. Walsh (Ed.) Counseling psychology and optimal human functioning (pp. 151-169). Mahwah: Erlbaum.

Sullivan, S.E., \& Arthur, M.B. (2006). The evolution of the boundaryless career concept: Examining physical and psychological mobility. Journal of Vocational Behavior, 69, 19-29.

Wegener, D.T., \& Fabrigar, L.R. (2000). Analysis and design for nonexperimental data: Adressing causal and noncausal hypotheses. In Reis, H.T. \& Judd, C.M. (Eds.), Handbook of research methods in social and personality psychology (pp. 412450). Cambridge: Cambridge University Press.

Wilson, M. (2005). Constructing measures: An item response modeling approach. Mahwah: Erlbaum.

Wood, J.M., Tataryn, D.J., \& Gorsuch, R.L. (1996). Effects of under- and overextraction on principal axis factor analysis with varimax rotation. Psychological Methods, 1, 354-365.

Wright, B.D., \& Masters, G.N. (1982). Rating scale analysis. Chicago: MESA.

Wright, B.D., \& Stone, M.H. (1979). Best test design. Chicago: MESA. 